\title{
Carnets
}

Revue électronique d'études françaises de l'APEF

Première Série - 2| 2010

L'équivoque

\section{Équivoque et ironie dans la poésie satirique contre la cantatrice Anna Zamperini à Lisbonne (1772)}

\section{Marie-Noëlle Ciccia}

\section{(2) OpenEdition}

\section{Journals}

Édition électronique

URL : http://journals.openedition.org/carnets/4591

DOI : 10.4000/carnets.4591

ISSN : 1646-7698

Éditeur

APEF

Édition imprimée

Date de publication : 1 janvier 2010

Pagination : 81-91

Référence électronique

Marie-Noëlle Ciccia, «Équivoque et ironie dans la poésie satirique contre la cantatrice Anna Zamperini à Lisbonne (1772) », Carnets [En ligne], Première Série - 2 | 2010, mis en ligne le 16 juin 2018, consulté le 01 mai 2019. URL : http://journals.openedition.org/carnets/4591 ; DOI : 10.4000/carnets.4591

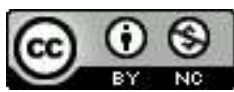

Carnets est mis à disposition selon les termes de la licence Creative Commons - Atribution - Pas d'utilisation commerciale 4.0 International. 


\title{
EQUIVOQUE ET IRONIE DANS LA POESIE SATIRIQUE CONTRE LA CANTATRICE ANNA ZAMPERINI A LISBONNE (1772)
}

\author{
MARIE-NOËLLE CICCIA \\ Université Paul-Valéry - Montpellier III \\ marienoelle.ciccia@gmail.com
}

\begin{abstract}
Résumé
Célèbre cantatrice italienne, Anna Zamperini est arrivée au Portugal en 1772 et fut bien vite l'objet et la victime de poésies satiriques lui reprochant ses mœurs peu vertueuses. Si cette critique s'exprime de façon explicite et sans détours sous la plume de certains poètes, elle ne manque pas de saveur dans des poèmes de caractère ironique dont l'expression bifide implique une lecture plus fine qui sache reconnaître l'équivocité des mots.

On perçoit l'équivoque non seulement dans la forme mais aussi dans l'intention «politique " du poète : le discours satirique, d'expression apparemment libre, obéit de facto à l'idéologie du pouvoir pombalin en matière de morale et d'identité nationale, deux concepts intimement liés, comme on tentera de le montrer dans cette étude.
\end{abstract}

\section{Abstract}

Famous Italian singer, Anna Zamperini arrived in Portugal in 1772. She was soon victim of satirical poets who blamed her for being a woman of easy virtue. If this critical appreciation is clearly explained by a certain number of them, it is also enjoyable in ironical poems which ambiguous expression entails a more subtle reading able to spot the equivocal words.

The double-edged discourse can be discovered not only in the form but also in the political intention of the poet: the satire, which seems to be a free speech, obeys, as a matter of fact, the Pombal's ideology with regard to morality and national identity, two close concepts in those days.

Mots-clés: Zamperini, équivoque, poésie satirique, ironie, identité nationale, pouvoir pombalin.

Keywords: Zamperini, equivocal, satirical poetry, irony, national identity, Pombal's power. 
Le recueil Zamperineida d'Alberto Pimentel $(1907)^{1}$ doit son titre à Anna Zamperini, célèbre cantatrice vénitienne en tournée au Portugal au début des années 1770, dont la beauté et la voix éveillèrent autant de fascination que de hargne dans le monde culturel de la Lisbonne pombaline. La célèbre «guerre» opposant les poètes de l'Arcádia Lusitana à ceux de la Ribeira das Naus doit en partie sa recrudescence en 1772 aux manières, semble-t-il assez lestes, de la diva qui, outre ses fantaisies vestimentaires, accueillait chez elle - à en croire les langues effilées - les hommes en vue de la capitale, surtout s'ils possédaient des biens... Étrange et scandaleuse, la Zamperini fut ainsi l'objet de vers dithyrambiques vantant sa beauté et ses qualités d'artiste, notamment de la part du père Manuel de Macedo qui lui consacra une ode. Mais elle souffrit également de l'opprobre de poètes dont certains sont passés à la postérité, tel Nicolau Tolentino ${ }^{2}$. La communauté masculine lisboète ne fut pas la seule à s'émouvoir pour elle. Un Français, le Chevalier de Montigny, chargé des affaires de la France à Lisbonne, s'amouracha de la belle Italienne et lui consacra également une épître en vers de mirliton dont les premiers alexandrins soulignent la candeur :

Zamperini, mes yeux te trouvent si jolie,

Que mon esprit pour toi veut faire une folie :

Tes charmes tous les jours font bien des fous divers,

Mais le plus fou c'est moi qui t'adresse des vers. (Pimentel, 1907 : 232-235)

L'amoureux, probablement éconduit faute de n'être essentiellement riche que de ses sentiments pour elle, n'eut guère le temps de faire la cour à la cantatrice puisqu'il mourut en août 1773. Son enterrement à Lisbonne fut accompagné par les membres de la communauté française de la capitale portugaise, ainsi que par un certain nombre de ministre étrangers.

Si, comme celle du Chevalier de Montigny, la plupart des poésies qui composent le recueil de Pimentel présentent un langage parfaitement clair, qu'il appartienne au registre de l'éloge ou à celui du sarcasme, d'autres au contraire sont d'un abord plus ambigu, nécessitant de la part du récepteur une capacité à la double lecture ou, du moins, l'obligeant à adopter une position plus défiante : les mots revêtent-ils véritablement le sens qu'ils paraissent avoir de prime abord? L'ironie constitue souvent le mode de cette expression biaisée. Ainsi, les fameuses décimas de Nicolau Tolentino «Defesa da Zamperini contra

\footnotetext{
${ }^{1}$ Ce recueil est la retranscription de deux manuscrits contenant des poèmes relatifs à la Zamperini, l'un conservé à la Bibliothèque Nationale de Lisbonne (Zamparineida Métrica, laudativa, satírica ou Colecção das Obras Poéticas, pró e contra, feitas em Lisboa à Cantora Italiana Anna Zamparine e ao Padre Manuel de Macedo, 1774 - BNL, Reservados, COD. 8630), l'autre aux Archives Nationales de la Torre do Tombo (Zamperineida Macédica, Métrica, Crítica, Satírica ou Colecção das Obras Poéticas, com seu Rabo-leva prozaico que se tem feito à Cantora Italiana Anna Zamparine e seu apaixanado [sic] o $P^{e}$ Manoel de Macedo em Lisboa de 1772 a 1773, un volume, 2 tomes de 20 et 25 feuillets recto-verso - ANTT, Livraria, ${ }^{\circ} 76$ ).

${ }^{2}$ Voir notre première étude sur la Zamperineida (Ciccia, 2009).
} 
duas décimas desaforadas que saíram contra ela » (Pimentel, $1907: 89-93$ ) débutent-elles par un discours prétendument bienveillant envers la diva flétrie par des «versos impertinentes » et que Tolentino prétend réhabiliter aux yeux de ses compatriotes. II ne faut pourtant pas s'y fier : le poète, en prenant cette apparente posture contre bon nombre de ses acolytes rimailleurs, se qualifie lui-même de Don Quichotte dans les premiers vers; en d'autres termes, en se mettant au service de la belle, il lutte contre des moulins à vent. La Zamperini est davantage une Aldonza qu'une Dulcinée... La suite du texte, d'une ironie acerbe et d'un langage parfois obscène, laisse peu de doute quant à l'opinion de Tolentino à son endroit ! Ce dernier se situe dans la droite ligne de la pratique de la satire au Portugal, genre destiné à corriger les mœurs tout en distrayant les lecteurs ${ }^{3}$. Vivement critique, ce langage ironique n'en est pas moins destiné à divertir le récepteur du texte. II se distingue pourtant d'une autre modalité, plus ludique encore, du discours à double sens: l'équivoque. L'équivoque ne permet aucun doute sur l'interprétation des paroles du prédicateur mais implique de la part du récepteur un autre type de décodification du discours, non plus fondé sur le principe de l'ironie (dire quelque chose en faisant entendre le contraire de ce que l'on dit) mais sur le double sens des termes choisis. Le récepteur doit pour cela détenir une connaissance « lexicale » lui permettant d'attribuer à des mots employés dans un contexte précis, un second sens qui, justement, n'appartient pas à ce contexte. Tout l'art de l'équivoque réside dans ce langage bifide qui dissimule avec plus ou moins d'adresse son double sens, qui manipule l'ironie fine mais aussi parfois l'obscénité et l'outrance sous des aspects respectables, voire plaisants.

Nulle question de passer ici au crible l'ensemble des compositions ironiques du recueil Zamperineida mais plutôt de nous intéresser à un long poème anonyme constitué de 24 dizains, ayant pour titre «Habilidade da Zamperini, exposta nas seguintes décimas » (Pimentel, pp. 149-158), dont on trouvera la retranscription intégrale en annexe. Les strophes 3 à 13 sont bâties sur un langage équivoque jouant sur les diverses interprétations de termes musicaux, à priori familiers de la cantatrice et adaptés au monde culturel dans lequel elle évolue. Passant de l'humour suscité par les sous-entendus érotiques, voire véritablement scabreux en début de texte, le poète finit par invectiver sa victime dans les dernières strophes.

Après un bref exposé des procédés de l'équivoque utilisés ici, il s'agira dans un premier temps de nous interroger sur leurs effets - voulus ou induits - sur le récepteur du poème. II apparaît toutefois que l'équivoque lexicale va au-delà du simple jeu de mots. Passé le premier décryptage des termes employés, n'existe-t-il pas un second palier de

\footnotetext{
3 “L'existence même de la satire met en jeu deux notions essentielles : celle, héritage de l'humanisme, d'un pouvoir de la parole et du poète dans la société, et celle d'une littérature qui puisse être à la fois agréable et utile, c'est-à-dire une littérature qui consolide les mœurs sans renoncer à ses propres charmes." (BRIOT, 1995 : 127 134)
} 
l'équivocité, liée à la doctrine dissimulée sous le premier message perceptible, celui de la moquerie critique? L'équivocité de l'ironie ici déployée n'est-elle pas davantage destinée à préserver une cohésion sociale qu'à détruire un individu ? Derrière la façade « burlesque » des termes équivoques se cache une perception de l'identité nationale que la Zamperini est censée mettre en danger, une identité nationale elle-même bien équivoque et bien malaisée à définir.

\section{Équivoque : de l'humour à l'invective}

Les 24 dizains qui composent ce poème ne sont pas tous de la même teneur et s'organisent en deux mouvements distincts. Les 13 premières strophes constituent une description de la Zamperini, adressée aux musiciens de son orchestre, description fondée sur l'équivoque sémantique de termes musicaux familiers de tous les gens de la profession. Les 11 dizains suivants, en revanche, apostrophent directement la cantatrice et appartiennent le plus souvent au registre de l'explicite. L'équivoque disparaît alors car, passé le moment de la grasse plaisanterie, amusante à décrypter, vient le temps de la vindicte et de la morale. II s'agit plus ici de laisser de place au doute et à l'ambigüité : la Zamperini est malfaisante et le message qui lui est adressé est clair. Les « bons mots » décelables ici ou là sont de l'ordre du maldizer: l'attaque est incisive et la blessure directe. Nous avons ici affaire, au fond, à la réactualisation à la mode néo-classique d'une pratique poétique entretenue depuis le temps des troubadours, celle la satire personnelle.

Intéressons-nous tout d'abord au premier mouvement du poème, bâti sur l'équivocité lexicale. Pour que l'équivoque fonctionne, il importe en premier lieu de «tromper»le récepteur, de le lancer sur une fausse piste afin de l'amener ensuite à débusquer les indices qui lui permettront de décoder le message de l'auteur, dans un rapport de complicité avec lui. Le rire est déclenché au moment où la double interprétation est devenue possible grâce à la perspicacité du récepteur. C'est ainsi que les deux premiers dizains, à l'exception du dernier distique du second, apostrophent sur le mode grandiloquent les musiciens amateurs de bel canto afin qu'ils prêtent l'oreille à la voix de la " singular Zamparini », supérieure à la «célebre Falchine »" (Pimentel, 1907 : 149). L'adjectif singular prend un sens équivoque lorsque l'on connaît la teneur des vers suivants mais, à la première lecture, alors qu'il est associé à la suavidade de la diva, il ne laisse entendre que son caractère unique, extraordinaire. La strophe suivante, enflée par d'emphatiques adjectifs de quantité (tal, tanto/a), par l'indéfini todo(s), par le superlatif maior ainsi que par un choix de vocables soulignant sa supériorité (primor, adiantar, mestra, excesso), introduit, de façon insidieuse, le

\footnotetext{
${ }^{4}$ Gertrude Falchini, fameuse soprano aigüe connue en 1771 pour son interprétation d'un opéra de Mozart.
} 
doute chez le récepteur grâce au jeu de dérivation autour du verbe compor. Le double compõe et le substantif composição ne relèveraient en effet que de la figure de style (polyptote) si le terme compostura associé au verbe vender (dans le dernier vers), ne modifiait pas totalement et brutalement le ton du poème. Ainsi, alors que l'incipit du texte guide le récepteur sur la voie de l'éloge, les vers « $E$ ela, a todos por bom preço / Vende a sua compostura » invitent inopinément ce dernier à signer avec l'auteur ce qu'Olinda Kleiman, évoquant le langage équivoque de Gil Vicente dans le Pranto de Maria Parda, nomme « Le pacte de connivence »:

Les règles du jeu, connues des deux parties, sont les suivantes : un meneur de jeu mystificateur, virtuose du langage, possédant le secret des mots, avec lesquels il sait jongler, doit s'évertuer à brouiller les cartes autant que faire se peut ; face à lui, un adversaire, spectateur ou lecteur, conscient de jouer le rôle de dupe, mais qui sait aussi dans quelle direction il faut chercher, se tient perpétuellement en éveil pour éviter les embûches et percer le maximum d'énigmes : à la clef, le rire, dont l'intensité dépendra de sa clairvoyance. [...] Le jeu, toutefois, s'exerce à des degrés divers et le résultat sera plus ou moins satisfaisant, selon que le joueur sera plus ou moins perspicace. [...] Le texte régi par l'accord tacite que je viens d'évoquer doit ainsi faire l'objet d'une interprétation à deux étages, voire plus (Kleiman, $1996: 6-7$ ).

Notre texte est sans doute moins énigmatique que celui de Gil Vicente, ne serait-ce que par sa plus grande proximité temporelle avec notre époque ; il n'en reste pas moins que l'on peut parfois constater une certaine adresse dans l'usage polysémique des termes musicaux qui, disséminés dans les strophes suivantes, exigent l' «interprétation à deux étages » définie par Olinda Kleiman. La besogne est facilitée par les italiques utilisés pour signaler les termes en question; on remarque à ce propos que dans les deux premiers dizains, compor, composição et figura ne sont pas en italique, signe qu'il convient de les comprendre dans leur premier sens, à l'inverse de leur emploi dans les vers postérieurs. Le basculement de ton intervenant dans le dernier distique du second dizain est aussi plaisant que brutal et c'est à la suite de ce soudain changement de tonalité que le poète va pour ainsi dire s'acharner à humilier la cantatrice par l'emploi détourné du vocabulaire technique musical, débutant sa harangue par un «com efeito » qui introduit tout bonnement la glose des deux vers assassins précédemment cités. On y apprend donc que la Zamperini est lascive et excite bel et bien physiquement les musiciens de l'orchestre (" as figuras»). Les allusions érotiques du type « No cantochão a preceito / Expõe o seu diapasão. / E à obra metendo mão, / Com afectos e ternuras, / Mete a compasso as figuras, / E as põe em suave união » sont assez explicites et sans doute aisées à repérer dans la mesure où certaines sont connues depuis l'époque des cantigas de escárnio e maldizer, telle «meter a 
compasso », qui apparaît avec un double sens érotique dans la composition «Joan Rodriguez foi osmar a Balteira », de D. Afonso X, roi de Léon et Castille ${ }^{5}$. On peut noter, du reste, l'impression de lascivité suscitée par l'usage à cinq reprises dans cette première partie de l'adjectif suave ou de son substantif suavidade. Le poète se plaît également à jouer avec les assonances ou les allitérations comme ici « da solfa do fundo fosso » (8ème dizain). Le son de la fricative [f] donnerait probablement de la fluidité au vers s'il n'était associé à une image particulièrement graveleuse. Cependant cette douceur est rythmée, comme il est « naturel » s'agissant de musique, par l'activité de la diva que l'on comprend être le chant, si l'on s'en tient évidemment au seul premier niveau sémantique. Les noms des notes de musique sont toutefois évocateurs. La «fusa (triple croche), évoquée dans le sixième dizain, désigne également a meretriz (la prostituée) et, associée au substantif «infusão » (dérivé de infundir dont l'un des sens est “s'introduire ») puis, dans les trois dizains suivants, à une série de verbes appartenant au même champ sémantique ("enxerir », « meter »- deux fois -, « introduzir »-deux fois -, « encaixar ») confirme le type d'activité à laquelle elle s'adonne à en croire le poète. La «bela colcheia » rappelle le colchão (la couche) que la Zamperini utilise pour ses « extravagâncias » avec les musiciens mais aussi les chanteurs de la troupe (le «falsete», le «contralto »...). Quant aux autres notes («breves», "semi-breves »...) elles donnent une idée de son rythme effréné (le « compasso » évoqué à plusieurs reprises, la « cadência ») associé à sa volonté d'aller au plus haut de sa voix (premier palier de sens) mais aussi de son plaisir («O tiple só por subir / A mais alta consonância, / Lho meteu com gosto e ânsia; / E meio ponto subido, / Forma ansiosa o sustenido / Com grave extravagância »). II va de soi que la taille des notes (mínima et máxima) doit prendre le sens métaphorique de la taille des attributs masculins des musiciens de l'orchestre auxquels elle accorde sans distinction ses faveurs.

L'ensemble des 13 premiers dizains fonctionne sur ce principe et il est peu utile de poursuivre ici l'inventaire minutieux de toute une gamme de vocables aisés à détourner de leur sens premier pour obtenir un discours d'une gaillardise, voire d'une obscénité étonnante, faisant de cette malheureuse diva une véritable nymphomane. Les derniers vers du 13ème dizain, qui forment la conclusion de ce premier mouvement et sont adressés à la «cantora prodigiosa », confirment l'ironie de cet ensemble par l'usage euphémistique (à l'inverse du discours tenu jusque-là) de termes prétendument aimables:

E como assim, singular,

Sabes bem desempenhar

Com os teus belos primores,

$\mathrm{Na}$ arte dos teus amores,

A solfa do namorar!

\footnotetext{
5 Site Experiências Poéticas Digitais, http://users.prof2000.pt/lemomig/articles.asp?id=4\&page=2, consulté le $17 / 08 / 2009$.
} 
Les pointes assassines de cette composition sont sans doute blâmables sur le plan moral car absolument gratuites, vouées à blesser la femme et même à détruire sa réputation sans qu'on décèle à la première lecture la véritable visée de cette attaque. Cependant, on ne peut nier une certaine virtuosité de la part du poète à manier l'équivoque et la métaphore grivoise, à enrichir le fond par la forme, notamment par le choix soigneux des rimes, riches pour la plupart, et qui donnent rythme et musicalité à l'ensemble. Du coup, on peut juger dommageable que le poète ne s'en tienne pas là et ne mette un point final à sa composition après le 13ème dizain. Au contraire, changeant de registre dans les strophes suivantes, il interpèle directement la diva à la deuxième personne du singulier: le temps de la leçon de morale est arrivé.

\section{Discours moral, discours équivoque}

Comme on a pu le discerner dans les lignes précédentes, c'est la tradition de la cantiga de escárnio e maldizer qui se perpétue dans ce long poème, y compris dans la forme puisque la composition est constituée de dizains en redondilhas maiores du type espinela (Cunha et Cintra, 1995 : 707), formant une espèce d'ode grotesque, dans la tradition du sirventés provençal :

Se os cantares d'amor galego-portugueses nos mergulham numa atmosfera ideal porque literatura palaciana, convencional e puramente intelectualizada, os cantares de escárnio e maldizer nos atiram violentamente na vida real do tempo: é o que sucede com o sirventês provençal (Spina, 2003 : 203).

Ce type de composition pouvant à la fois relever de la satire et de la politique était autrefois un moyen pour les troubadours d'exprimer leurs passions et même leur haine contre leurs seigneurs ; par la suite, il servit à censurer les désordres de la société, à lui reprocher ses erreurs et ses défauts. Le poème qui nous occupe est motivé par les mêmes raisons. En effet, cette série d'équivoques destinée à ridiculiser une personne est, en première lecture, de l'ordre de la gaudriole. Le but, ludique dans un premier temps, consiste à obtenir la complicité du récepteur pour se gausser d'un individu. La Zamperini semble impuissante à réagir dans la mesure où elle ne dispose pas du pouvoir lui permettant de faire taire ou de censurer le rimailleur. Au plaisir de la moquerie, de l'escárnio, s'ajoute en outre la satire sociale (la correction des mœurs nécessaire à une société bien policée). Cette complicité partagée devient une « action », au sens où elle implique d'autres conséquences que le simple divertissement; elle se veut porteuse d'une certaine efficacité car, en 
confrontant le railleur et son public avec un raillé dont il ne fait pas doute que ses comportements sont jugés détestables, l'équivoque devient une arme, à l'instar de l'ironie.

On passe de l'équivoque à l'ironie dans le second mouvement du texte où le discours est plus ambigu ${ }^{6}$ car, une fois encore, le poète met son lecteur sur une fausse piste durant les dizains 14 et 15 et la moitié du 16. Sur le mode élogieux, il se met à comparer les qualités artistiques de la Zamperini avec celles d'une danseuse nommée affectueusement Annina dont il parle au passé et qui pourrait être la célèbre Marie-Anne de Camargo (17101770), danseuse française d'origine espagnole ${ }^{7}$, décédée deux ans plus tôt. La Camargo avait, en effet, une solide réputation (ce qui corroborerait le vers du $14^{\text {ème }}$ dizain «Essa decantada Annina »), était dotée d'une grâce sans pareille dans le mouvement (« galhardo gesto ») mais, surtout, devait sa renommée à sa vertu et à son honnêteté («O modo honesto », «o proceder rico e honesto »). Cette comparaison apparemment flatteuse se trouve discrètement atténuée par le vers «imitas o modo honesto » car si la diva imite la Camargo, c'est que son propre comportement est affecté : son honnêteté n'est que de façade (on en aura, du reste, la confirmation au dizain 17). La strophe suivante, filant la comparaison entre les deux femmes, ne peut que reconnaître la maîtrise de l'art vocal de la Zamperini que nul, du reste, ne pouvait lui nier. Mais il semble que c'est pour mieux la dénigrer dans les vers suivants car, l' « ardentia » et le « quente ser » renvoient sans tarder à des aspects bien plus triviaux de sa personne. II n'est plus question ici d'équivoque. Le poète instille graduellement l'ironie dans ces dizains 14-17 ; c'est pourquoi l'échange entre émetteur et destinataire est plus ambigu, car le mode employé est le sous-entendu. II importe de décoder ce discours de façon différente de l'équivoque qui n'est au fond qu'un jeu de devinettes. L'ironie implique l'interprétation potentiellement hasardeuse car, selon les termes de Philippe Hamon repris par Marie-Hélène Larochelle, elle se révèle "une communication fragile, à hauts risques, qui présente plusieurs dangers » (Larochelle, 2004 : §5), notamment celui l'incompréhension de la part du récepteur qui peut douter de sa lecture, demeurer dans l'incertitude, faisant perdre du même coup au discours ironique sa puissance et son charme. Si le récepteur n'a pas saisi les enjeux du discours, il laisse échapper la raison d'être de ce dernier. Aussi, pour que l'ironie soit comprise, la narration doit se ponctuer de signaux qui établissent une distance par rapport au propos, affirme

\footnotetext{
6 "L'ironie implique un discours antiphrastique et suppose donc un engagement argumentatif ambigu". (Larochelle :2004).

${ }^{7}$ Elle fut admirée par Voltaire qui lui dédia ces vers :

Ah ! Camargo que vous êtes brillante!

Mais que Sallé, grands Dieux, est ravissante!

Que vos pas sont légers \& que les siens sont doux!

Elle est inimitable, \& vous toujours nouvelle;

Les Nymphes sautent comme vous,

Et les Grâces dansent comme elle.
} 
M.Hélène Larochelle qui prend l'exemple précis de l'exagération, de la comparaison et de la métaphore (Larochelle, 2004 : §18).

À partir du $18^{\text {ème }}$ dizain, plus question d'ambigüité ironique dans le discours qui atteint un palier supérieur dans l'offensive. II semble que l'ironie ne soit pas suffisamment efficace pour le poète qui a recours à l'invective : «L'accueil de l'ironie est variable d'un lecteur à l'autre de sorte qu'il importe d'aussi envisager la possibilité limite de cette forme d'énonciation : l'invective »(Larochelle, 2004 : §1). L'invective engage encore davantage l'émetteur du discours qui transgresse clairement les règles de sociabilité et use de violence dans le but de heurter la sensibilité de sa victime.

L'invective s'envisage comme un acte performatif impliquant un ethos ou un pathos agressifs. En outre, une invective s'avère une parole intentionnellement agressive ou une parole entendue comme une agression. L'ethos et le pathos agressifs apparaissent comme des paramètres essentiels à la définition de la violence verbale (Larochelle, 2004 : §32).

L'invective s'accompagne d'humour car il importe de préserver l'aspect ludique qui, loin d'être innocent, est un vecteur non négligeable d'un discours moral sérieux. C'est pourquoi le poète estime judicieux d'introduire des termes grivois dans le but de déclencher le rire quelque peu gras. Sans plus aucune ambigüité, la Zamperini est accusée de vendre son corps, sa chair (« a carne ») au plus offrant. La gradation de la force du lexique accompagne un discours également bien construit sur le plan rhétorique, selon le schéma suivant :

- interpellation de la diva («Dize» - deux fois) : elle est sommée de prêter attention au poète ;

- interrogations («Por que... ?» - deux fois) : sa conduite déconcertante et inattendue appelle des explications de sa part ;

- châtiment appliqué par le poète qui se fait « justicier »

\author{
Se hás mister de ser sangrada \\ Nessa cutânea selecta \\ Com a mentual lanceta \\ Eu te darei a picada;
}

- admonestation et conseils (« livra-te destes trabalhos », « recolhe-te ao vestiário ») ;

- moralité finale : n'en supportant pas davantage et ayant, au fond, rempli son devoir de moralisateur, le poète quitte dignement le théâtre : « [...] eu já deixo a plateia; / Pois sou por melhor ideia / De tais figuras contrário.» 
La tradition du maldizer semble donc ici bien maintenue. Cependant, au-delà de la Zamperini vilipendée pour ses manières peu recommandables, il est clair que c'est à toute une société que le prédicateur s'adresse. En fustigeant la diva, avec la verdeur que l'on a pu constater, le moraliste s'engage dans le domaine d'une politique sociale bien connue, menée par le marquis de Pombal : la correction des mœurs. Ainsi, l'on est passé de l'équivoque des mots dans la première partie du poème à l'équivoque du sens dans la seconde : une double interprétation s'impose car la cantatrice n'est pas la seule cible du prédicateur. La violence des mots est rédemptrice ; elle est d'une certaine façon cathartique. L'épisode spécifique Zamperini permet aux femmes de se «laver » en quelque sorte de leur « hybris » potentielle ou avérée. À ce titre les deux derniers dizains sont éclairants : en recommandant à Anna Zamperini de modifier son comportement, le poète élargit imperceptiblement le champ aux « damas » qui perdent toute valeur morale et esthétique en cas de manquement à la vertu :

\footnotetext{
Livra-te desses trabalhos,

Por que fazem com que as damas,

Amolecendo-Ihes as [mamas],

Fiquem uns penderucalhos:

E elas ficam uns bandalhos,

Sendo à vontade infiéis,

Rebeldes do gosto às leis;

Que pois já valor não têm,

Se valiam um vintém,

Não vêm a valer dez réis.
}

Cette exhortation à la morale et aux bonnes mœurs est un thème classique de la poésie et du théâtre de cette période et, en brisant prétendument un tabou par le choix d'un langage hardi, voire violent, autrement dit en se plaçant en marge de la bienséance et de la civilité, en donnant l'illusion de sa totale liberté de parole, le poète obéit - peut-être involontairement - à de véritables contraintes liées à la politique nationale. II en va de l'identité nationale portugaise que Pombal défend avec ardeur. Les satires contre la Zamperini ont très souvent souligné le fait qu'elle était une étrangère, qui plus est, une étrangère qui semait le trouble dans la société portugaise, un véritable «Dionysos au féminin » (Ciccia, 2009). Le poète enfonce ici le clou en opposant à nouveau les étrangères aux Portugaises. Ces dernières sont vertueuses et, partant, plus belles (« têm mais garbo do que elas »). Celles qui, comme cette Zamperini venue d'ailleurs, dérogent à ces lois morales « não vêm a valer dez réis ». La dernière strophe est univoque sur ce plan :

\footnotetext{
Nunca estrangeiras mais belas

Alcançaram pico igual;

Há damas de Portugal,

Que têm mais garbo do que elas;

Quanto mais do que as mozuelas

Desse Teatro adversário:

Recolhe-te ao vestiário,
} 
Porque eu já deixo a plateia;

Pois sou por melhor ideia

De tais figuras contrário.

II importe cependant de lire le message à un autre niveau et, de fait, découvrir le caractère équivoque de l'ensemble : la Zamperini n'est qu'un prétexte à l'exaltation de l'identité nationale portugaise. Les derniers vers sont totalement dénués d'humour car le moment est grave. Le poète demande sévèrement à la cantatrice d'abandonner la scène; de son côté, il quitte le parterre du théâtre car, en dépit des apparences langagières, son sérieux l'oppose définitivement aux hommes dépravés qui, depuis la "plateia" de la salle de spectacle, n'ont de cesse d'admirer la diva. Le prédicateur n'est pas qu'un simple rimailleur aigriard et paillard; il est un homme honnête et digne de son pays. II représente cette identité nationale portugaise bien plus utopique que réelle: une société morale et mesurée dans son ensemble, dont les éventuels comportements déviants sont à corriger comme le fait ici l'auteur anonyme d'un sonnet emprunté au même recueil :

Famosos amadores Zamperinos,

Que tão mal empregais vossas finezas,

As discretas Senhoras Portuguesas

Não podem crer os vossos desatinos (Pimentel, 1907, 229).

\section{Bibliographie}

\section{Monographies}

CunHA, Celso et CINTRA, Lindley (11 ${ }^{\text {ème }}$ édition: 1995). Nova Gramática do Português Contemporâneo. Lisboa: Edições João da Costa.

FONSECA, Pedro José da (1817). Tratado de Versificação Portuguesa. Lisboa: Tipografia Lacerdina.

PIMENTEL, Alberto (1907). Zamperineida - Segundo um Manuscrito da Biblioteca Nacional. Lisboa: Livraria Central.

Spina, Segismundo (2 ${ }^{\mathrm{ème}}$ éditon : 2003). Manual de Versificação Românica Medieval. São Paulo : Ateliê Editorial.

\section{Articles de revues}

CıccıA, Marie-Noëlle (2009). «Du choc esthétique à l'onde de choc identitaire: Anna Zamperini ou Dionysos dans le Portugal pombalin ». Revue Quadrant, Université PaulValéry - Montpellier III, $\mathrm{n}{ }^{\circ 25}$ (sous presse).

KLEIMAN, Olinda (1996). «Maria Parda: Le vin des étoiles ». Revue Quadrant, Université Paul-Valéry - Montpellier III, $n^{\circ} 13$, pp. 5-26.

LAROCHELLE, Marie-Hélène (2004). «Équivoque d'une agression. Relecture du Nez qui voque de Réjean Ducharme ». Revue Études littéraires, Université de Laval, Volume 36, 
numéro 2, 2004, p. 91-104. URL : http://id.erudit.org/iderudit/012905ar. Consulté le 17 août 2009.

RIBARD, Dinah et SchapIRA, Nicolas (2004). «Équivoque, écriture et action : éléments de discussion avec Jean-Pierre Cavaillé ", Les Cahiers du Centre de Recherches Historiques, 33 | 2004, mis en ligne le 05 septembre 2008. URL : http://ccrh.revues.org/index257.html. Consulté le 17 août 2009.

\section{Sources digitales}

Experiências poéticas digitais (2004)

<URL : http://users. prof2000.pt/lemomig/articles.asp?id=4\&page=2>

CALADO, Ana Isabel, "Sirventês". E-dicionário de termos literários (2005).

<URL: http://www2.fcsh.unl.pt/edtl/verbetes/S/sirventes.htm> Consulté le 18 août 2009. 
ANNEXE

Habilidade da Zamperini exposta nas seguintes décimas

(Alberto Pimentel, Zamperineida, pp. 149-158)

1.

Olá, músicos, amantes

Que sois da solfa magana

De Amor, já que tendes gana

De ouvi-la, vinde flamantes:

Ouvi, e aprendei constantes,

Não da célebre Falchine

Nem já da nossa Sistine,

Mas dessa (valha a verdade)

que o faz com mais suavidade,

A singular Zamparini.

2.

Não só com tal primor canta,

Mas também, conforme o exposto,

Diz, compõe com tanto gosto,

Que à maior mestra se adianta:

Compõe sim, com graça tanta,

Que a composição procura

Todo o cantor de figura

Comprá-la com todo o excesso;

E ela, a todos por bom preço

Vende a sua compostura.

3.

Zamparini com efeito,

Que a solfa quer pôr em grade,

E usar do tempo que agrade,

Destra, arma a grade a seu jeito:

No cantochão a preceito

Expõe o seu diapasão.

E à obra metendo mão,

Com afectos e ternuras,

Mete a compasso as figuras,

$E$ as põe em suave união.

4.

As figuras sem desar,

Faz ela subir de ponto,

Por que neste contra-ponto,

É mestra mais singular:

Pois não só faz alterar,

Quando os afectos procura,

Toda a máxima figura;

E ainda a mínima, e bem,

A faz exaltar também

Com suavidade e doçura.

5.

Para no próprio lugar

Meter a figura longa,

Faz com que esta se prolonga,

Sem sua extensão recear:

Antes de mais longa estar

Se agrada sem embaraços;

$E$ que em seus quatro compassos 
Exercite o seu ofício;

E por este benefício,

Lhe dá mil beijos e abraços.

6.

Usa também do seu breve

Que dois compassos só tinha;

Mas já longo hoje a ser vinha

Sem poder ser semibreve:

Também a usar se deteve

Da sua bela colcheia,

Mas inda à semicolcheia,

$E$ à seguinte que se usa

Figura chamada fusa,

Da infusão desta se anseia.

\section{7.}

Para as vozes the enxerir, Vê a que o valor Ihe dá, Do u, ré, mi, fa, sol, lá, Com que as veio a distinguir; O tiple só por subir A mais alta consonância, Lho meteu com gosto e ânsia; E meio ponto subido, Forma ansiosa o sustenido Com grave extravagância.

\section{8.}

Sem receio ou sobressalto No lugar do seu destino, Por ser o mais genuíno, Também lhe mete o contralto: $E$ por que não fique falto De tenor seu movimento, Lho introduz, e num momento, Da solfa no fundo fosso, Por baixo lhe encaixa o grosso, que é todo o seu fundamento.

9.

Aos compassos do seu gosto, Já morosos, já velozes, Introduzidas as vozes, Formou da solfa o composto:

$E$ já com alegre rosto Pela experiência comprova Que se vai a fazer prova Solfejando a compostura; Como canta por natura O seu gosto mais se prova.

10.

Canta alegro; mas no canto No alegro apressada vai, Como nesse alegro assai Que causa na fuga espanto:

Nesta, é toda um mero encanto, Porque com modo belíssimo, E com um gosto finíssimo, 
Muito suave e elegante, Forma esse alegro brilhante,

Forma esse alegro prestíssimo.

11.

Em usar não se embaraça

Nessa sua compostura,

Dessa tres-quialta [sic] figura,

Porque as três mete com graça

Sem que uma ou outra Ihe faça

Algum pejo desigual,

Nem tampouco lhe faz mal

Baixem por bemol agora,

Pois por bequadro sem mora

Torna a coisa ao natural.

12.

Na cadência em tom suave

Forma o trino soberano,

Já com terno som piano,

Já com forte, com som grave:

Sem que aos ouvidos agrave,

Também canta por falsete

E a voz natural já mete;

E porque fica mais doce

O seu canto a mezza-voce,

A suavidade repete.

13.

Por que fique a fuga airosa,

Segundo cá o reputo,

Forma um belo sustenuto,

$\mathrm{E}$ a deixa assim mais graciosa:

oh, cantora prodigiosa!

E como assim, singular,

Sabes bem desempenhar

Com os teus belos primores,

$\mathrm{Na}$ arte dos teus amores,

A solfa do namorar!

14.

Tu, Zamparini, tão fina

És nessa arte de cantar,

Como foi na de dançar

Essa decantada Annina:

Dessa guapa dançarina,

Que era de galhardo gesto,

Imitas o modo honesto:

Dela herdaste esses teus bens;

Pois como ela tinha, tens

Proceder rico e honesto.

15.

Tu cantas, ela dançava;

Cantas tu com suave tom,

E parece que ela ao som

Do teu canto, é que bailava;

Do baile ela se prezava;

Tu te prezas do teu canto;

Tu cantando vales tanto, 
Quanto ela bailando. Atento:

Bailando, ela era portento;

Cantando, tu és encanto!

16.

Ela dançando fazia

O que sabemos, e vimos;

Tu cantando como ouvimos,

Fazes mais por essa via;

Mais, porque a tua ardentia,

À da tal Annina excede,

Tanto quanto lhe precede

O que nessa arte praticas,

$E$ a vantagem com que ficas,

De mais quente ser procede.

17.

Mas as vantagens que gozas

consistem só na aparência;

Porém não porque na essência

Sejam prendas vantajosas:

Sem vantagens, venturosas

Annina e tu são no belo;

São o mesmo paralelo,

e a prová-lo assim me obrigo

Pues qual mas qual menos digo

Que toda la lana és pelo.

18.

Sendo pois isto como é, e o mostra a razão bem clara, Por que te vendes tão cara, Que formam de ti má fé? Mas já sei que isto é por que O Quattrine te recreia,

E a ambição toda te anseia, $E$ te faz, por que te encarne, Pródiga da tua carne,

E avara da carne alheia.

19.

A Annina não era assim, Porque a quem a galanteava Nos consta que premiava Com liberal frenezim;

Mas tu só é "venha a mim"

E usando de ambiciosa ânsia,

A esses com petulância,

A mais fina e refinada,

Por ficares substanciada

Lhe tiras toda a substância.

20.

Dize, por que tão vilmente

Esse estipêndio assim cobras?

Dize já por que assim obras

Acções, que não são de gente?

Se é por estares demente;

Por que algum de airada vida

De quem tu foste querida, 
Te feriu, indo-te aos covos?

Deixa-me bater dois ovos

Para curar(-te) a ferida.

21.

Se hás mister de ser sangrada

Nessa cutânea selecta

Com a mentual lanceta

Eu te darei a picada:

Se a veia ficar rasgada,

Mais do que é conveniente,

Bem podes afoitamente

Tu curá-la em caso tal,

Com leite que é virginal,

Que é para isso excelente.

22.

E se estás esquentadinha,

Mais quer dessa febre o abalo

Que te dêem carne de galo,

Do que carne de galinha:

Ora abre lá a boquinha:

Irra! E de carne que troços!

Cruz! Inteiros, duros, grossos,

Engoles sem que te esfolem!

As que assim a carne engolem,

A vêm [mijar] em [ossos]. (1)

23.

Livra-te desses trabalhos,

Por que fazem com que as damas,

Amolecendo-Ihes as [mamas],

Fiquem uns penderucalhos:

E elas ficam uns bandalhos,

Sendo à vontade infiéis,

Rebeldes do gosto às leis;

Que pois já valor não têm,

Se valiam um vintém,

Não vêm a valer dez réis.

24.

Nunca estrangeiras mais belas

Alcançaram pico igual;

Há damas de Portugal,

Que têm mais garbo do que elas;

Quanto mais do que as mozuelas (2)

Desse Teatro adversário:

Recolhe-te ao vestiário,

Porque eu já deixo a plateia;

Pois sou por melhor ideia

De tais figuras contrário.

(1) Termes non retranscrits par Pimentel. Apparaissent dans le manuscrit COD 8630.

(2) « as mussuelas », selon le manuscrit COD 8630. 